\title{
PUSHING THE FRONTIERS OF RADIOBIOLOGY: A SPECIAL FEATURE IN MEMORY OF SIR OLIVER SCOTT AND PROFESSOR JACK FOWLER: COMMENTARY
}

\section{Commemoration of Jack Fowler's life, work, impact and legacy}

\author{
JOLYON H HENDRY, DSC \\ Department of Medical Physics, Christie Hospital, Manchester, UK \\ Address correspondence to: Prof Jolyon H Hendry \\ E-mail: jhendry2002uk@yahoo.com
}

\section{ABSTRACT}

Jack Fowler [formally Professor John Francis Fowler PhD, DSc, MD (Hon), FInstP, FRCR, FBIR, FAAPM, FASTRO, FACRO] was a remarkable scientist, known to many in the field of clinical radiation biology as at the forefront of applying linear-quadratic dose-fractionation-time modelling to help improve a wide range of cancer treatments using radiotherapy. His death on 1st December 2016 after a long career of 60 years was marked by Obituaries in six scientific journals in his field e.g..$^{1-4}$ Jack is remembered for his quantification of biologically effective dose in a wide variety of radiotherapy practices and modified protocols (supported by experimental-system studies), his extensive publications, his didactic lecturing and teaching abilities, and his warm personality.

Jack trained as a Medical Physicist in Newcastle in the 1950s and then worked in London, becoming Professor of Medical Physics at Hammersmith Hospital before taking over the Directorship of the Gray Laboratory from Oliver Scott at Mount Vernon Hospital in 1970 for the next 18 years. That period was extremely fruitful, with an enormous scientific output of publications from Jack and staff members including Ged Adams, Adrian Begg, Julie Denekamp, Mike Joiner, Nic McNally, Barry Michael, Fiona Stewart, Boris Vojnovic, Peter Wardman and George Wilson, who all became eminent scientists in their own specialties. Jack's interest in dose fractionation started with his involvement in the British Institute of Radiology radiotherapy trials conducted by Frank Ellis in the 1960-70s, and the neutron therapy trials at Hammersmith Hospital. Then in the early 1980s there was a paradigm shift in the considered mechanisms and models of dose-fractionation-time relationships for normal tissue and tumour responses, stimulated variously by Eddie Barendsen, Jack and the Houston group of Howard Thames, Rodney Withers, Lester Peters, Gilbert Fletcher. ${ }^{5}$ The previous Ellis formula for tolerance doses, based on empirical power functions of number of fractions and overall treatment time, was not consistent with radiobiological principles of responses and emerging evidence in support. It was gradually replaced by the Linear-quadratic (LQ) formula, which was based on the high importance of dose per fraction as well as number of fractions, and a time factor present after a lag or kick-off time for tumours and early tissue reactions. One flourishing area of work at the Gray Laboratory, in which Jack was deeply involved using experimental systems, was to establish $\alpha / \beta$ values (characterising the tissue/tumour sensitivity to changes in dose per fraction) and their applicable dose range for many normal tissue types and organs such as skin, lung, bladder and kidney. Jack realised the potential and great importance of this methodology in the radiotherapy of cancer patients, ${ }^{6}$ and that determined his scientific direction for the rest of his life. His own account of this ${ }^{7,8}$ was also recorded in interview by ASTRO. ${ }^{9}$ His amicable nature and infectious enthusiasm were appreciated by students, fellows, radiation biologists, medical physicists, trainee and practicing radiation oncologists alike, when he gave didactic lectures and taught them the principles of LQ/BED (Biologically Effective Dose) modelling and some of its particular applications.

Some examples of the applications involving Jack for head and neck cancer included construction of the novel CHART (Continuous Hyperfractionated Accelerated RadioTherapy) trial schedule, calculation of the time factor in conventional radiotherapy for tumours in that site and the involved normal tissues from international outcome results, and BED analysis of effects of time, dose, and fractionation on temporal lobe necrosis following radiotherapy of nasopharyngeal carcinoma. Regarding non-small-cell 
Figure 1. Collated photographs of Jack and colleagues.

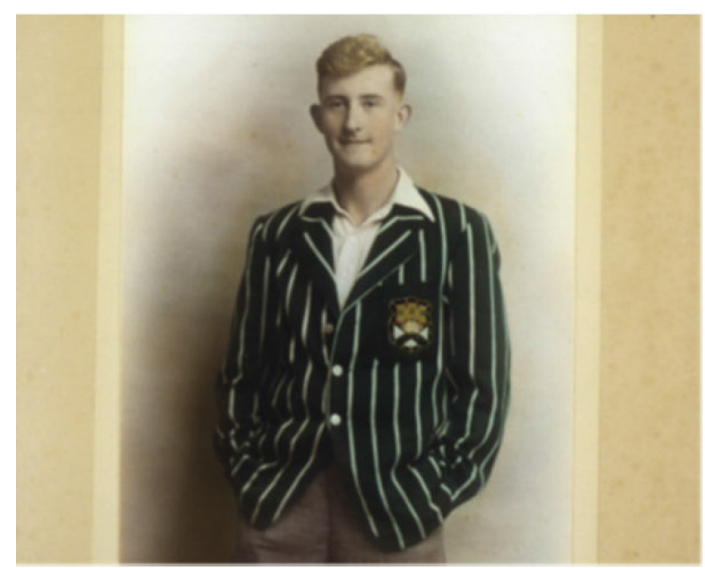

Jack Fowler, University of London student circa 1942

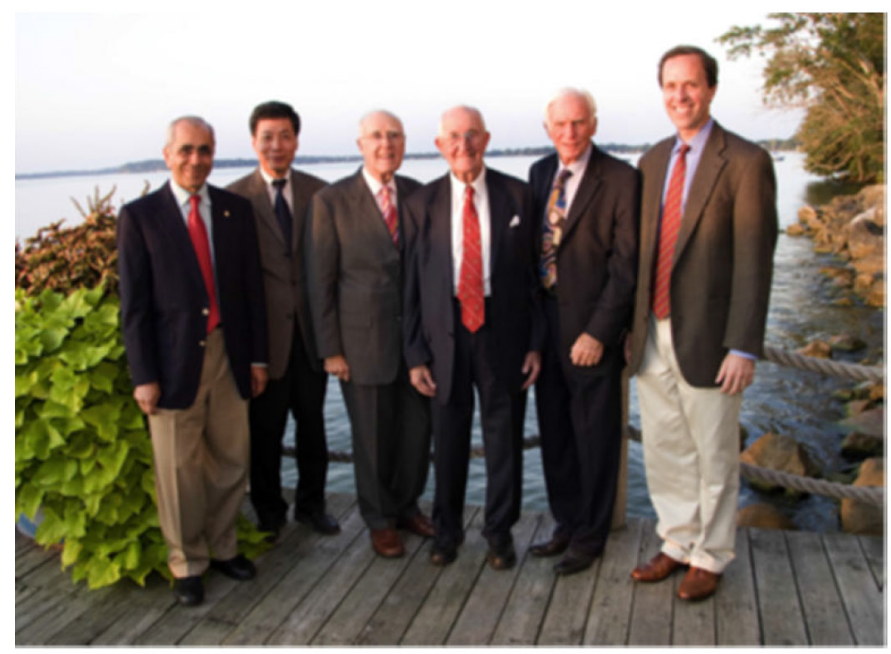

Bhudatt Paliwal, Kian Ang,

Eric Hall, Jack Fowler, Rod Withers, Paul Harari.

Madison, Wisconsin, 2009

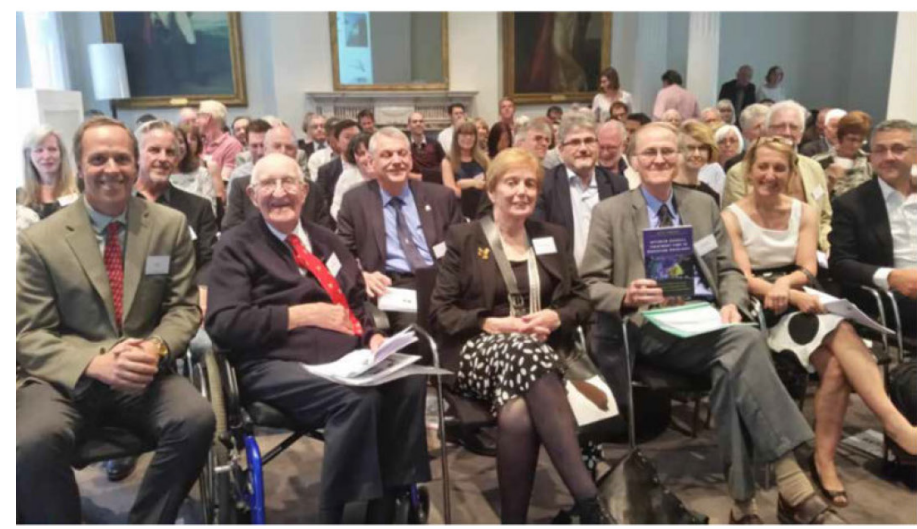

Jack's Symposium, London, 2015

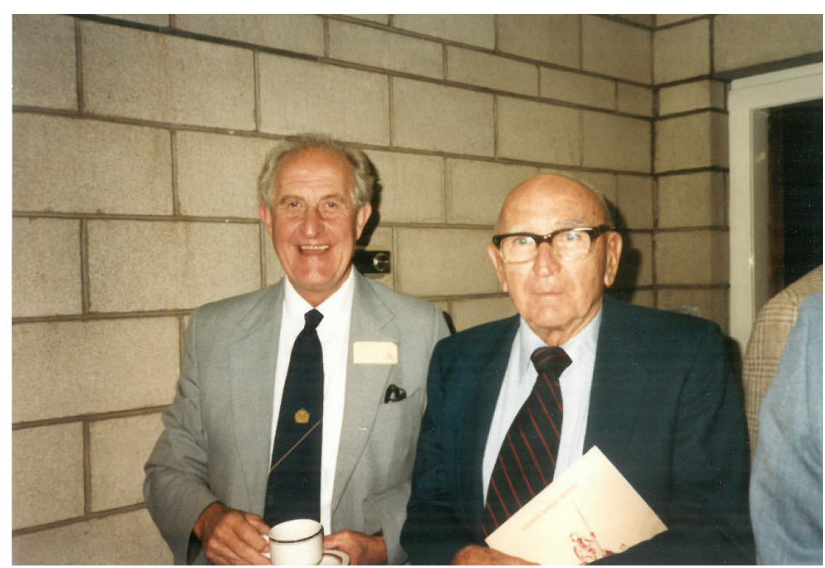

Jack and Gilbert Fletcher, Scotland, 1962

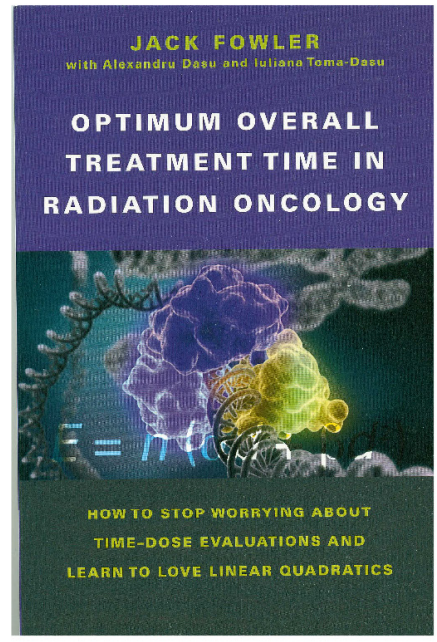

Jack's book, 2014

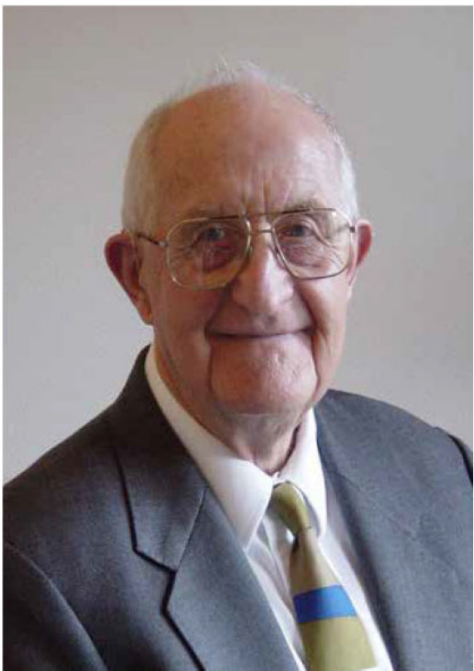

Jack, still working! 
lung cancer, calculations from outcome data showed that those tumours repopulated rapidly during radiotherapy, responses were predicted from the larger fractions in shorter overall times that were being used in several countries, and he favoured protons over intensity-modulated photons for dose escalation studies. For cervix cancer, calculations were performed to predict biologically-equivalent doses when changing from low-dose-rate to medium-dose-rate and then high-dose-rate brachytherapy, as well as quantifying the adverse effects of treatment prolongation. These modelling papers generally were very well received, albeit with a few disagreements such as regarding the very low value of $\alpha / \beta$ for prostate cancer, ${ }^{10}$ since confirmed in randomised trials. ${ }^{11}$ In addition to these site-specific studies, there were also generic radiotherapy issues addressed such as the loss of biological effect in prolonged fraction delivery which is particularly important if cobalt-60 machines are used after many years of operation and isotope decay, and another issue of why the presence of shorter half-times of repair may lead to greater damage using pulsed brachytherapy unless they are taken into account.

When he retired officially, rather than developing other hobbies like some people do, he was free of responsibilities and this gave him much further opportunity to travel, lecture and teach widely which he loved to do. He had regular engagements in Madison, Leuven and Umea, as well as close contact with colleagues in Montevideo, Gliwice and many other places. Jack published a wealth of over 550 scientific papers and 2 books, one on "Particle radiotherapy" in $1981^{12}$ and the other on "Optimum overall treatment time in radiation oncology" in $2014^{8}$ when he was age 89 , with Alexander Dasu and Iuliana Toma-Dasu. He received many awards including the BIR Roentgen Prize (1965), the ESTRO Breur Medal (1983), the Juan del Regato Gold Medal (1984), the Gilbert Fletcher Society Gold Medal (1986), the ASTRO Gold Medal (1995), and the RRS Failla Award (2002). Also, Jack was variously President of the Hospital Physicists Association, the European Society of Radiation Biology, and the British Institute of Radiology. At a family level, he and his first wife Kathleen had a great seven children, and his second wife Anna provided excellent support for the latter part of his life.

A major impact and legacy of Jack's work is his extensive use of radiobiological modelling (LQ/BED etc) to address a broad variety of radiotherapy practices and problems regarding optimal radiation scheduling for cancer treatment, as detailed above. There were also immediate applications in routine practice, for example in management of dosage errors and unintended treatment interruptions, ${ }^{13}$ in comparing existing fractionation schedules where certain percentage tolerance BEDs could be determined for organs at risk, and in providing a rational method for adjusting dose when dose-rate changed (with Roger Dale, e.g. ${ }^{14}$ ). Such applications have helped in improving the consistency and safety of the entire practice of radiotherapy. Also, Jack was one of a group of professionals who believed that optimal fractionated radiotherapy still had not been reached for many cancer types. Improvements which could be modelled and tested would not rely necessarily on the use of the conventional daily dose-fraction size of $2 \mathrm{~Gy}$, hence leading to the successful explorations of hyper-(<1.8 Gy per fraction), hypo-( $>2.0 \mathrm{~Gy}$ per fraction), and accelerated fractionation (shortening overall treatment time). In addition, many current trial protocols for modified fractionation and comparative reviews of the efficacy of different radiotherapy schedules, now use BED and associated parameter values like EQD2 (EQuivalent Dose in 2 Gy fractions) to predict, describe, or compare outcomes $\left[\right.$ e.g. $\left.{ }^{15}\right]$, and Jack made a big contribution to the use of those quantitative measures. He will be remembered not only for his many pertinent contributions and by the several generations of people who worked with him and/or learnt from him, but also by the ESTRO "Jack Fowler University of Wisconsin Award to honour an outstanding junior investigator", and the Radiation Research Society "Jack Fowler Award, provided by the University of Wisconsin to honour the achievements of Professor Jack Fowler. The award recognizes an outstanding junior investigator/faculty for exceptional work in radiation oncology, medical physics, and/or radiobiology."

With virtual certainty, Jack (Figure 1) would have relished working further in the current trends such as towards the benefits of using inhomogeneous dose-(painting) distributions, particle therapies, newer combination treatments and more-personalised radiotherapy. All of these are helped by modelling to suggest and guide new protocols, with outcomes and comparative benefits feeding into model refinements, as exemplified by Jack's extensive contributions.

Professor Jolyon H Hendry, Manchester, UK

\section{REFERENCES}

1. Hendry JH, Jones B. Professor John Francis 'Jack' Fowler D.Sc. F.Inst.P. (1925-2016). Radiother Oncol 2016; 121: 478-9. doi: https://doi.org/10.1016/j.radonc.2016.12.011

2. Jones B, Hendry J. Professor Jack Fowler and Sir Oliver Scott. Br J Radiol 2017; 90: 20160904.o. doi: https://doi.org/10.1259/bjr. 20160904.0

3. Yarnold J, Hoskin P, Hendry J, Jones B. Professor John Francis 'Jack' Fowler D.Sc. (1925-2016). Clin Oncol 2017; 29: e90-e91. doi: https://doi.org/10.1016/j.clon.2016.12. 007

4. Harari PM, Ritter MA, van der Kogel AJ. Obituary and Tribute to John "Jack" Francis Fowler, PhD, DSc (1925-2016). Int J Radiat Oncol Biol Phys 2017; 97: 886-8. doi: https:// doi.org/10.1016/j.ijrobp.2017.01.015

5. Thames HD, Withers HR, Peters LJ, Fletcher GH. Changes in early and late radiation responses with altered dose fractionation: implications for dose-survival relationships. Int J Radiat Oncol Biol Phys 1982; 8: 219-26. doi: https://doi.org/10.1016/03603016(82)90517-X

6. Fowler JF. Fractionated radiation therapy after Strandquist. Acta Radiol Oncol 1984; 23: 209-16. doi: https://doi.org/10.3109/ 02841868409136014

7. Fowler JF. 21 years of biologically effective dose. Br J Radiol 2010; 83: 554: 554: 68. doi: https://doi.org/10.1259/bjr/31372149 
8. Fowler JF, with Dasu A, Toma-Dasu I. Optimum overall treatment time in radiation oncology. Madison, WI, USA: Medical Physics Publishing; 2014. pp. 1-93.

9. Fowler JF. An interview with John F. Fowler, DSc, PhD, FASTRO. 2013. Available from: https://www.astro.org/About-ASTRO/ History/John-F-Fowler/

10. Fowler JF. In reply to Dr. Lee. Int J Radiat Oncol Biol Phys 2009; 74: 1332-3. doi: https://doi.org/10.1016/j.ijrobp.2009.04.065

11. Royce TJ, Lee DH, Keum N, Permpalung $\mathrm{N}$, Chiew CJ, Epstein S, et al. Conventional versus hypofractionated radiation therapy for localized prostate cancer: a meta-analysis of randomized noninferiority trials. Eur Urol Focus 2017; pii: S2405-4569: 30251-1. doi: https://doi.org/10.1016/j.euf.2017.10.011

12. Fowler JF. . In: Nuclear particles in cancer treatment. Medical physics handbook. vol. 8. . UK: Institute of Physics; 1981. pp. 1-178.

13. RCR. The timely delivery of radical radiotherapy: standards and guidelines for the management of unscheduled treatment interruptions. 3rd ed. UK: The Royal College of Radiologists; 2008.
14. Dale RG, Fowler JF. Radiation repair mechanisms. In: Dale R. G, Jones B, eds. Radiobiological Modelling in Radiation Oncology. UK: British Institute of Radiology; 2007. pp. 1-292.

15. Soh F-Y, James ML, Hickey BE, Daly T, Jeffery M, See AM, et al. Altered radiation fractionation schedules for clinically localised and locally advanced prostate cancer. Cochrane Database Syst Rev 2015; 155. doi: https://doi.org/10.1002/14651858. CD011462 